\title{
DOPRINOS CLIL-A SAVREMENIM TOKOVIMA NASTAVE STRANOG JEZIKA
}

\author{
MILOŠ ĐERIĆ 1 \\ Galindo škola stranih jezika \\ Beograd, Srbija
}

Komunikativni pristup u podučavanju drugog jezika (L2) uveliko je ušao u škole brojnih, a različitih obrazovnih sistema širom sveta. Reforme koje prate kako društveno-političke, tako i vaspitno-obrazovne tendencije u zemlji i inostranstvu zahtevaju još jasnije ciljeve u implementaciji produktivnog usvajanja drugog, odnosno stranog, jezika u obrazovnim sistemima. Jedan od takvih, sve uspešnijih modela u metodici nastave stranog jezika jeste i integrisano učenje sadržaja i jezika (eng. Content and language integrated learning, (LIL). Sve popularniji na svetskoj sceni, CLIL metod predstavlja rešenje za motivisanje učenika, podučavanje u vezi sa lingvističkim aspektima stranog jezika, ali kroz usvajanje opšteobrazovnih znanja i postizanja ishoda koji su primenjivi, ne samo u oblasti socijalne komunikacije, već i u akademskom napredovanju ka složenim procesima razmišljanja. Pošto se javlja niz objektivnih prepreka u ostvarivanju ciljeva uspešnog CLIL metoda, ovaj rad pruža uvid u osnovne karakteristike koje doprinose pospešivanju uspeha u CLIL učionici. Kako bi praktičari u učionici što uspešnije dosegli potencijal CLIL-a, rad pruža uvid u osobine i razvoj (LIL-a (u inostranstvu i Srbiji), ali i efekte koji se postižu njegovom pravilnom primenom. Zaključujem da CLIL ima perspektivu u Srbiji, kao što ima i van granica zemlje. Rad se osvrće i na neke od prepreka na koje treba obratiti pažnju u implementaciji ovog vida nastave i predlaže dalje sfere istraživanja.

Ključne reči: CLIL, prednosti, L2, motivacija, sadržaj.

1 Kontakt podaci (Email): mdbgd@sbb.rs 


\section{UVOD}

Integrisano učenje sadržaja i jezika, u daljem toku rada CLIL (eng. Content and Language integrated Learning), predstavalja sve prisutniju, savremenu metodu u primeni podučavanja drugog jezika (L2), odnosno stranog jezika. Veliki broj istraživanja ukazuje na značajan potencijal koji CLIL nastava ima, kao odličan sadržaj jezičkog inputa, koji odgovara jednoj vrsti hipertekstualnog pristupa informacijama kojima su učenici dvadeset i prvog veka izloženi. Pored izrazite popularnosti koju stiče u Evropi, a i šire, postoji niz otvorenih pitanja u vezi sa metodološkim implikacijama, a samim tim i sa izborom nastavnih jedinica, kao i realizacijom nastave od strane nastavnika jer je ovaj model podučavanja i dalje nedovoljno ispitan i organizovan kroz adekvatne pedagoške materijale. Ovaj rad ima za cilj da predstavi prednosti primene CLIL-a u nastavi kao izvora podsticajnih i potkrepljujućih sadržaja čiji je cilj sticanje novih predmetnih znanja kroz jezik cilj, a ne samo znanja o stranom jeziku. CLIL metoda povezuje proces učenja sa praktičnom primenom jezika koja se poklapa sa iskustvima i interesovanjima učenika, što ih motiviše u procesu učenja. Razvoj međupredmetne kompetencije i unapređivanje znanja i komunikativnih sposobnosti važni su za budućnost srpskog obrazovnog sistema sa ciljem što bliže integracije sa evropskim obrazovnim vrednostima.

Struktura rada sastoji se od uvodnih napomena koje postavljaju ciljeve, zatim od poglavlja koje definiše CLIL i daje kratak uvid u njegov razvoj. U centralnom delu rada, autor se bavi opisom glavnih karakteristika i prednosti ove metode, koje mogu pospešiti realizaciju nastave u našem obrazovnom sistemu. Kako se naš region ne nalazi na mapi primene CLIL-a u formalnom školskom obrazovanju, važno je napomenuti i da se lična iskustva, na koja će se autor rada osvrnuti, odnose na takozvani „delimični CLIL"2 , što podrazumeva deo nastave na engleskom jeziku koji se sprovodi u nekim bilingvalnim školama i školama stranih jezika u Beogradu. U ovom delu biće uspostavljena veza CLIL-a sa razvojem međupredmetnih komepetencija u našem obrazovnom sistemu, kao potpora stremljenju da učenici stranog jezika ne budu izloženi samo jeziku udžbenika za strane jezike, koji je često jednoličan, repetitivan iz godine u godinu i ne podstiče produbljivanje opšteg obrazovanja i shvatanja stranog jezika kao sredstva daljeg obrazovanja, a ne samo snalaženja u socijalnom kontekstu u nekoj stranoj zemlji. Sa ciljem podrške važnosti učenja stranih jezika u obrazovno-vaspitnom sistemu, rad će predstaviti uspešnu primenu CLIL modela u nastavi, kao jednog od ključnih faktora doprinosa postepenoj modernizaciji obrazovnog sistema na našim prostorima (Durbaba et al. 2017: 5). U završnom delu rada autor navodi potencijalne prepreke u ostvarivanju ovakvog vida nastave, a zatim zaključuje koji opšti potencijal sadrži CLIL nastava i daje preporuke za dalja istraživanja u ovoj oblasti.

2 Autor rada uvodi termin i u daljem radu će biti korišćen u značenju nastave koja sadrži neke od primarnih osobina CLIL-a. 


\section{ODREĐENJE POJMA CLIL-A}

Integrisano učenje sadržaja i jezika predstavlja zajednički imenitelj nekolicini sličnih pristupa u evropskoj tendenciji objedinjavanja sadržaja školskih predmeta i učenja stanog jezika. Pomenuću, najpre, bilingvalnu sadržajnu nastavu (eng. Bilingual Content Teaching), bilingvalnu predmentnu nastavu (eng. Bilingual Subject Teaching) i jezičku nastavu baziranu na sadržaju (eng. Content-based Language Teaching) (Papaja 2010: 5-6). U sledećem poglavlju biće više reči o podeli i sadržaju bilingvalne nastave.

Koncept CLIL metode „baziran je na pretpostavci da se strani jezici najbolje uče kada se u učionici ne fokusira toliko na jezik, koliko na sadržaj koji se prenosi kroz jezik. Novina u ovom pristupu jeste da sadržaj proučavanja u učionici nije u velikoj meri preuzet iz svakodnevnog života već iz sadržaja drugih predmeta poput matematike, biologije, geografije, itd"3 (Wolff 2003: 211-222). Marš percipira CLIL kao „generički termin koji se odnosi na bilo koju obrazovnu situaciju u kojoj se neki dodatni jezik, a da nije najčešće korišćeni jezik u okruženju, koristi u nastavi i učenju nejezičkih predmeta"4 (Marsh i Langé 2000: iii). Sam akronim (LIL nastao je početkom devedesetih godina u Evropi i predstavljao je nastavu sa fokusom na strani jezik koji se upotrebljava u nastavi u kojoj sadržaj nije jezički, i gde jezik i sadržaj imaju zajedničku i korisnu ulogu (Beko, 2013: 8). Valja dodati i da prvo 'L' u okviru akronima (LIL koje se odnosi na jezik (eng. language), označava bilo koji strani jezik, ali zapravo se u praksi najčešće misli na engleski jezik, kao dominantan CLIL jezik i bilo bi besmisleno poricati njegovu dominaciju (Beko 2013: 13). Ipak, autor se osvrće i na sprovođenje CLIL nastave u odeljenjima u kojima se uče i drugi svetski jezici.

CLIL kao metoda podučavanja stranog jezika većje postala prihvaćena širom sveta. Moram naglasiti da je to još jedna sveža tema u lingvističkim ispitivanjima, te podleže različitim klasifikacijama i sadržajima. Pored termina CLIL, evropske struje, javlja se i američka verzija pod imenom CBI (eng. Content based instruction), što predstavlja nastavu u učionici u kojoj se neki sadržaj tj. drugi predmet predaje kroz L2 koji učenici u tom trenutku usvajaju (Tedick i Cammarata 2012).

Cilj CLIL-a u nastavi se poklapa sa ciljevima usvajanja stranog jezika, odnosno stvaranjem uslova za učenje koji će odgovarati što prirodnijem učenju jezika, obezbeđivanju razloga i uslova za upotrebu stranog jezika u učionici, podsticanju učenja putem ukazivanja na pozitivne efekte fokusa na značenje u odnosu na fokus na formu, kao i naglašenom povećanju izlaganja ciljnom, stranom jeziku (Dalton-Puffer 2007: 3; Dalton-Puffer et al. 2009: 17-25). Neka dosadašnja istraživanja već su potvrdila uticaj koji CLIL ima u domenu nastave stranih jezika, pri čemu ima tendencija da u postignućima prevazilaze rezultate onih opcija koje nisu CLIL (Meyer 2013: 2). Postoji i grupa istraživanja koji ukazuju da učenici bolje usvajaju i samo gradivo koje kroz

3 The term CLIL is now the most commonly used and "it is based on the assumption that foreign languages are best learnt by focusing in the classroom not so much on language but on the content which is transmitted through language. The novelty of this approach is that classroom content is not so much taken from everyday life but rather from content subjects e.g. Mathematics, Biology, Geography etc".

4 "Content and language integrated learning (CLIL) is a generic term and refers to any educational situation in which an additional language and therefore not the most widely used language of the environment is used for the teaching and learning of subjects other than language itself". 
jezik uče, odnosno sadržaj u odnosu na učenike koji ne uče kroz CLIL model nastave (Badertscher 2009; Heine 2008). 0 doprinosu, više u poglavlju 5 ovog rada.

Neophodno je naglasiti da CLIL ne predstavlja novi oblik nastave stranih jezika, kao ni nejezičkih predmeta. Reč je pre svega o metodi koja podrazumeva inovativno stapanje ova dva oblika nastave. Kao što Zavišinova ističe, posrednički jezik u CLIL nastavi može biti, najpre, neki strani jezik učenika, kao što srećemo u slučaju italijanskog u bilingvalnom odeljenju u jednoj beogradskoj gimnaziji (autor rada dodaje i francuski i engleski jezik kao dodatne primere bilingvalnih odeljenja u Srbiji). Zatim, posrednički jezik može biti drugi jezik, kao na primer italijanski jezik u Italiji za imigrante. Naposletku, može biti ijezik nacionalnih manjina, odnosno jeziksa posebnim statusom, kao na primer francuski ili nemački jezik u Italiji koji uživaju poseban status u oblastima koje se graniče sa zemljama u kojima su ti jezici nacionalni i u kojima je prisutna brojna zajednica građana kojima je taj jezik maternji (Zavišin 2013: 26).

U konačnom osvrtu na razumevanje pojma CLIL treba istaći da povezanost nastave stranih jezika sa drugim nastavnim predmetima dovodi do razvoja međupredmetnih kompetencija, pored temeljnijeg opšteg obrazovanja, što potkrepljuje tvrdnju da CLIL podiže nivo lingvističkog znanja na nekoliko načina: ne samo da daje dodatnu izloženost, za učenike, lakše savladivom načinu sticanja znanja (Graddol 2006: 86), već kroz zadatke koji su kognitivno izazovni, a ubačeni u kontekst, utiču da učenik napreduje i u smislu sadržaja i u smislu jezika (Cummins i Swain 1986: 14). Svet u kome današnje mlade generacije žive obeležen je višejezičnošću i engleskim jezikom kao lingua franca. Školsko učenje treba shvatiti kao osnov za celoživotno usavršavanje, a strani jezik i kao sredstvo za dalji rad u privatne i profesionalne svrhe (Durbaba et al. 2017: 5).

\section{OSOBINE I SADRŽAJ CLIL NASTAVE}

Kako smo CLIL već definisali kao integrisanje jezika i sadržaja, pri čemu se dva elementa prepliću i pridaje im se jednak značaj, dalje in treba razviti i oba elementa dovesti do veoma visokog nivoa, držeći predavanje ne samo na, već sa i kroz strani jezik. Osobine CLIL-a najbolje su predstavljene kroz teorijski okvir pod imenom model $4 \mathrm{C}$ (Meyer 2013: 296). Model 4C ima holistički pristup, u kome se integrišu sadržaj, kognicija, komunikacija i kultura (Beko 2013: 8). Ovaj model predstavlja osnovu za planiranje CLIL časova, kao i konstruisanje nastavnog programa zbog svoje integrativne prirode. Pitanje sadržaja ne otvara samo pitanje usvajanja znanja i veština, već predstavlja mogućnost da učenici sami stvaraju sopstveno znanje i razviju veštine, što predstavlja personalizovano učenje. Kognicija ili spoznaja, bazira se na učenju i razmišljanju. Učenici treba da kreiraju svoju interpretaciju sadržaja. Procesi razmišljanja se analiziraju u svrhu lingvističkih potreba. Što se komunikacije tiče, jezik se vezuje za jezik u kontekstu i rekonstrukciju sadržaja povezanu sa kognitivnim procesima. Jezik treba da bude dostupan i transparentan, kao i da bude praćen interakcijom. Treba dodati i da je veza između kulture i jezika vrlo složena. Razvoj međukulturnih kompetencija je od fundamentalnog značaja za CLIL. Pošto se CLIL metod ne bazira na podučavanju jezika fokusiranom samo na gramatiku, on pospešivanjem sveukupnog kognitivnog razovoja opravdava svoju poziciju i u jačanju motivacije učenika (Lasagabaster i Sierra 2009: 5). 
Postoje nedoumice da li se neki program može smatrati dvojezičnim programom ili CLIL programom, a po mišljenju zagovornika CLIL-a, često to više zavisi od kulturnih i političkih principa nego od samih karakteristika programa. Sledeće karakteristike, koje ću navesti, daju tipične primere CLIL programa u Evropi, Južnoj Americi i mnogim delovima Azije (Lasagabaster i Sierra 2010: 4).

CLIL predstavlja upotrebu radnog jezika, odnosno onog jezika na kome se odvija nastava u školi, pa se sa njim učenici uglavnom susreću u učionici. Kao što je već napomenuto, dominantni CLIL jezik je engleski jezik, što potkrepljuje uverenje da se vladanje engleskim jezikom, kao dodatnim jezikom, posmatra kao ključna karakteristika pismenosti širom sveta. Realnost izvođenja CLIL nastave upozorava i na to da predavači često nisu izvorni govornici ciljnog jezika. Oni nisu, u većini slučajeva, ni stručnjaci iz oblasti datog stranog jezika, već su stručni u oblasti datog sadržaja, odnosno akademskih naučnih disciplina. Time se smatra da su CLIL predavanja uglavnom stavljena u nastavni plan kao predavanja sadržaja (npr. fizika, matematika, biologija), dok se ciljni jezik normalno nastavlja kao predmet sam za sebe, u formi predavanja na temu nekog stranog jezika, koja drže jezički stručnjaci. U okviru CLIL programa, uglavnom se više od 50\% nastavnog programa drži na ciljnom jeziku.

Glavni elementi CLIL metode razvrstani su u šest kategorija (Beko 2013: 19-21).

1. Elementi koji se baziraju na fokusu. Fokus je ovde, najpre, usmeren na učenje jezika kroz nastavu drugih predmeta. Dalje, zastupa se učenje drugih predmeta u nastavi jezika. U tom domenu može doći i do integrisanja nekoliko predmeta, što razvija interdisciplinarnost. Fokus na organizovanju učenja kroz kroskurikularne teme i projekte je, takođe, značajan. Najzad, podržavanje procesa razmišljanja tokom učenja jeste važan element ove grupe.

2. Elementi koji ukazuju na bogato okruženje za učenje su: korišćenje rutinskih aktivnosti i diskursa, prikazivanje jezika i sadržaja u učionici, izgradnja samopouzdanja učenika da eksperimentišu jezikom i sadržajem, korišćenje učionica kao centara učenja, upućivanje na razne pristupe autentičnim materijalima i ambijentima za učenje, povećanje svesti učenika o znanju jezika.

3. Elementi koji ukazuju na autentičnost su: sloboda učenika da traže jezičku pomoć kada im je potrebna, prilagođavanje interesima učenika, uspostavaljanje stalne veze između učenja i života učenika, povezivanje sa drugim govornicima CLIL jezika, korišćenje aktuelnih materijala iz medija i ostalih izvora.

4. Elementi koji podržavaju aktivno učenje su: učenici koriste jezik za vreme časa više od nastavnika, zatim pomažu u postavljanju sadržaja, jezika i jezičkih ishoda, učenici ocenjuju napredak u postizanju ishoda učenja. Ova grupa elemenata obuhvata i podsticanje vršnjačke saradnje u učenju, usaglašavanje značenja jezika i sadržaja sa učenicima, preuzimanje uloge fasilitatora.

5. Sledeća je grupa elemenata koja se odnosi na pomoć u procesu učenja koju učenik koristi. Ko-konstrukcija znanja (eng. Scaffolding) podrazumeva oslanjanje na učenikovo postojeće znanje, veštine, stavove, interesovanje i iskustvo, „prepakivanje” informacija na učeniku lak način, pozitivno 
reagovanje na različite stilove učenja, negovanje kreativnog i kritičkog učenja, podsticanje učenika da uvek napravi još jedan korak u istraživanju, a ne da ostane u udobnosti naučenog.

6. Elementi koji se odnose na saradnju su: planiranje kurseva/časova/tema u saradnji sa nastavnicima koji koriste, ali i onima koji ne koriste CLIL metodu, uključivanje stručnjaka izvan škole u učenje po CLIL metodi, kao i uključivanje lokalne zajednice, vlasti i stručne javnosti.

Pored navedenih osobina CLIL nastave, autor rada osvrće se i na različite realizacije sadržaja ovog vida nastave. U prvom delu ovog poglavlja pažnja je posvećena različitim osobinama CLIL metoda, pa će u ovom delu više reči biti o varijantama primene CLIL-a u nekim zemljama sveta, kao i u Srbiji.

Realizacija CLIL nastave, koja može biti izvedena delimično (ranije pomenuto) sa težnjom da bude potpuna, uglavnom se u praksi organizuje kroz bilingvalnu nastavu. Kada je reč o bilingvalnoj nastavi, autori pružaju različite stavove u vezi sa definisanjem ovog oblika nastave. Uzrok ove nedoumice nalazi se u određivanju ciljne grupe kojoj je ovakav oblik nastave namenjen, kao i u zadacima i ciljevima bilingvalnog programa. Bilingvalno obrazovanje predstavlja pojam koji se odnosi na škole u kojima se neki predmeti ili kompletna nastava vodi na dva jezika. Takav oblik nastave predstavlja jak model bilingvalnog obrazovanja. Postoji i slab model bilingvalnog obrazovanja u kojem je učenicima dozvoljeno da koriste svoj maternji jezik u kratkom, prelaznom periodu, nakon čega se manjinski jezik u potpunosti zamenjuje zvaničnim jezikom zajednice (Zavišin 2013: 97).

U skladu sa predmetom ovoga rada, autor je proučio primere bilingvalne nastave u kojima je, pored maternjeg, zastupljen strani jezik učenika kao posrednički jezik u nastavi. ${ }^{5}$

Finska vlada je krajem dvadesetog veka pokazala veliko interesovanje za strane jezike, pa je u škole uvela učenje stranog jezika od devete godine, dok učenici u jedanaestoj godini mogu fakultativno da se opredele za drugi strani jezik. Ovakva odluka predstavlja nastojanje vlade da se uspostavi ravnoteža sa engleskim jezikom, ali i da se poboljša opšta jezička kompetencija učenika. U skladu sa ovakvim težnjama, Ministarstvo prosvete Finske obrazovalo je radnu grupu koja podstiče uvođenje stranog jezikakao posredničkog jezika u tradicionalnim školama u Finskoj. Ministarstvo prosvete, dalje, preporučuje uvođenje stranog jezika kao posrednog jezika u obrazovanju (CLIL program) u svim školama u Finskoj. Finska se nalazi na čelu istraživanja kad je reč 0 otkrivanju novih tematskih polja u okviru bilingvalne nastave, koja su se javila u posebnim zahtevima današnje Evrope (Zavišin 2013: 101).

U Italiji, od 1999. godine svaka srednja škola u Italiji može, u skladu sa organizacionim mogućnostima i interesovanjima učenika, da primenjuje CLIL metodu. Uprava svake škole zadržava pravo da odluči koji predmet ili predmeti će se predavati na nekom stranom jeziku, kao i u kom obimu: da li će se nastava na stranom jeziku izvoditi za celokupni ili delimičan nastavni program. Od 2008. godine u skladu sa reformom italijanskog školskog sistema, za svaki smer gimnazije predviđeno je podučavanje jednog nejezičkog obaveznog predmeta na stranom jeziku za učenike svih razreda.

5 Za detaljne rezultate istraživanja videti Zavišin 2013 i Papaja 2010. 
Pored toga, za gimnazije jezičkog smera predviđeno je u prvom ciklusu izučavanje jednog nejezičkog predmeta na jednom stranom jeziku, dok se u drugom preporučuje da se jedan nejezički predmet izvodi na stranom jeziku koji bi bio drugačiji od onog u prvom ciklusu. Takođe je naglašeno da se izbor drugog stranog jezika sprovede u skladu sa zahtevima učenika i roditelja (Zavišin 2013: 103).

U Nemačkoj se posebno ističe francusko-nemačka gimnazija koja je ustanovljena 1963. godine. Od 1992. godine se u velikom broju srednjih škola uvodi poseban program - Content Based Bilingual Education (eng. (BBE) koji podrazumeva dvojezičnu nastavu u nastavi nejezičkih predmeta. Ova bilingvalna odeljenja su danas prisutna u različitim srednjim školama u kojima se nejezički predmeti predaju na stranom jeziku, dok je pored francuskog i engleskog jezika zastupljena i nastava na italijanskom, španskom, holandskom, ruskom i savremenom grčkom jeziku. U ovim školama je posebno izražena kulturna dimenzija nastave na stranom jeziku: $u$ njima su posredni strani jezici ujedno i sredstvo za bolje upoznavanje sa drugim kulturama.

U Španiji je došlo do povećanog interesovanja za CLIL nastavu od 2007. godine i ona se uvodi u tradicionalnim školama. Sprovođenje ovih programa podržavaju državne obrazovne institucije. Primena CLIL programa se razlikuje u zavisnosti od regije kojoj škola pripada: tako, na primer, u autonomnim pokrajinama jezici zajednica imaju španskim ustavom zagarantovan status, te tako imaju značajnu ulogu u obrazovnom sistemu. Kurikulum se može sprovoditi na najmanje dva jezika (na jednom se podučava jedna grupa predmeta, a na drugom druga grupa) i to na sledeći način: na državnom zvaničnom jeziku i na drugim zvaničnim jezicima, kao i na državnom zvaničnom jeziku i delimično na jednom ili dva strana jezika (Zavišin 2013: 104-105).

U Mađarskoj, bilingvalna nastava u kojoj je zastupljen jedan strani jezik kao posredni jezik u nastavi najmanje tri nejezička predmeta počela je da se primenjuje od 1987. godine. Prva dvojezična nastava se odvijala na engleskom, francuskom, nemačkom, španskom, italijanskom i ruskom jeziku (Vámos 1998). U najvećem broju škola zastupljen je dvojezični program na engleskom i nemačkom jeziku. U Mađarskoj se pokazalo da je, do sada, najbolje rezultate dao petogodišnji program, pre svega zbog pripremne godine u kojoj učenici usvajaju solidne jezičke osnove, kao i da je od presudnog značaja kompetencija nastavnika koja se ne odnosi samo na poznavanje stranog jezika, već prevashodno na primenu posebnih didaktičkih metoda.

Imerzioni program po kanadskom modelu označava takozvani program „potapanja" učenika u nastavu stranog jezika, u početku sa ograničenom upotrebom maternjeg jezika, dok se kasnije u potpunosti isključuje iz nastave. Ovaj program moguće je uvesti na bilo kom školskom nivou: od obdaništa do viših nivoa (Zavišin 2013: 114-115). S tim u vezi, moguće je izdvojiti tri glavne karakteristike imerzije po kanadskom modelu: 1) dostupnost kompetentnih dvojezičnih nastavnika kako na stranom, tako i na maternjem jeziku učenika; 2) korišćenje jezičke redundance i ponavljanja u nastavi, sa jakom težnjom nastavnika da stvori razumljiva uputstva na stranom jeziku, kako bi olakšali razumevanje učenicima; 3) u cilju formiranja aditivnog bilingvizma i pismenosti, podučavanje na maternjem jeziku u početnom periodu imerzije naglašeno je u ranom periodu, te nastava podrazumeva polovinu predmeta na maternjem jeziku. 


\section{RAZVOJ CLIL-A U SRBIJI}

Ministarstvo obrazovanja Srbije je 2000. godine pokrenulo nekoliko projekata koje su podržale mnoge međunarodne institucije, poput Svetske banke i Saveta Evrope, sa ciljem da se osavremeni opšti obrazovni sistem u zemlji. Tako je predviđen novi kurikularni okvir za strane jezike koji podrazumeva centralni položaj učenika u nastavnom procesu, kao i interdisciplinarni i modularni pristup nastavi. Ovim kurikulumom predviđeno je da se najmanje dva strana jezika uče tokom dvanaest godina osnovnog i srednjeg obrazovanja, kao i tri ili više jezika sa statusom izbornih predmeta. U okviru ovog projekta omogućeno je i uvođenje bilingvalne nastave na stranom jeziku u osnovnoj i srednjoj školi (Filipović et al. 2007: 234). Odlukom Ministarstva prosvete i sporta, bilingvalna nastava je uvedena u jednoj osnovnoj školi (na francuskom jeziku) i nekoliko gimnazija u zemlji (italijanski, francuski). S obzirom na to da zakon ne dozvoljava nastavu na stranom jeziku u osnovnoj školi, nastava se sprovodi na osnovu ogleda dvojezične nastave na srpskom i francuskom jeziku u osnovnom obrazovanju i vaspitanju. U srednjim školama nastava se odvija na osnovu projekta dvojezična nastava na srpskom i francuskom jeziku, odnosno na srpskom i italijanskom jeziku (Vučo 2006: 41). Reč je o takozvanom dualnom programu koji podrazumeva upotrebu maternjeg (srpski) i stranog jezika (italijanski) u podučavanju određenih predmeta tokom celokupnog školovanja (Zavišin 2013: 134-135).

Pored bilingvalnog obrazovanja u Srbiji, u svetlu sagledavanja CLIL nastave, zanimljivo je naglasiti da je i u našem obrazovnom sistemu započet i proces povezivanja učenja stranog jezika sa drugim predmetnim sadržajima, odnosno međupredmetnom saradnjom među nastavnicima u redovnom kurikulumu osnovnih škola. Izvor tog procesa jeste dalja reorganizacija obrazovnog sistema. U Srbiji danas imamo ustanovljene standarde, kao i očekivane ishode za sve strane jezike u oba ciklusa obrazovanja (osnovnoškolskom i srednjoškolskom) kojima se jasno definišu razvoj interkulturnih i međupredmetnih kompetencija. Povezanost nastave i učenja stranih jezika sa ostalim nastavnim predmetima doprinosi, ne samo temeljnijem opštem obrazovanju, već i razvoju međupredmetnih kompetencija. U najširem smislu, te kompetencije se odnose na kompleks znanja, veština, sposobnosti, stavova i motivacije upotrebljenih u različitim aktuelnim i budućim aktivnostima svakog učenika. Kod nas polako sazreva ideja da jezik ne mora da bude sagledan kao poseban predmet, potkrepljena primerima stranih obrazovnih sistema u kojima su ukinuti posebni nastavni programi za pojedinačne predmete i zamenjeni opšteobrazovnim kurikulumom. To pokazuje da se didaktički principi holističkog učenja mogu odnositi, ne samo na metode sticanja kompetencija, već i na nastavne sadržaje. Zato ciljevi učenja koji se temelje na razvoju međupredmetnih kompetencija omogućuju razne inovativne forme školskog rada, uključujući i one proistekle iz izmenjenih i tehnički unapređenih vidova učenja, a pogotovu iz prikupljanja i procesuiranja informacija, što će u budućnosti izvesno, sve više dobijati na značaju (Durbaba et al. 2017: 6). U našem obrazovnom sistemu, za sada, imamo škole koje primenjuju bilingvalnu nastavu, sa napomenom da se, ipak, ne radi o ravnomernoj upotrebi ciljnog jezika, već o tome da su neki sadržaji prilagođeni izvođenju na ciljnom jeziku. U tom smislu, može se reći da je naš obrazovni sistem već postavio temelje za razvoj međupredmetne kompetencije 
i unapređivanja znanja i komunikativnih sposobnosti u okviru nastave koji polako vodi ka delimičnoj upotrebi CLIL-a u svim školama, nadam se, u skorijoj budućnosti.

\section{POZITIVNI EFEKTI CLIL NASTAVE}

Istraživanja pokazuju da primena CLIL-a u nastavi dovodi do postizanja efekata na nekoliko nivoa: kod učenika i nastavnika, u školi i uopšteno u društvu. Zadržaću se na prednostima koje se reflektuju na učenike. Najpre, treba izdvojiti veći broj sati aktivne nastave koji se ostvaruje u nastavi stranog jezika. Slede i drugi doprinosi učenju stranog jezika: učenici su izloženi kvalitetnijem načinu učenja usled dubljeg procesuiranja; učenici su angažovani kroz zahtevne aktivnosti u akademskom i kognitivnom smislu; učenici se pripremaju za buduće profesije jer se (LIL nastava može porediti sa sadržajima iz poslova iz realnog života (Papaja 2010: 85).

Implementacija CLIL-a dovodi i do sledećih ishoda: podiže nivo motivacije; učenici koriste sve svoje kapacitete; podiže nivo interulturne svesti učenika (Beko 2013: 21). Motivacija je važan uslov uspešnog učenja jezika. Osvrnuću se na dva osnovna tipa motivacije: integrativna motivacija (želja da se bude deo ciljne jezičke kulture iz emocionalnih razloga) i instrumentalna motivacija (želja da se jezik nauči iz ličnih praktičnih razloga) (Gardner 2006). Kako učenik stiče više opšteg znanja krozškolovanje, tako opada njegova motivacija u nastavi stranog jezika zbog nemogućnosti da svoje znanje iznese na tom jeziku. Javljaju se dva osnovna faktora koja utiču na oblikovanje motivacije kod učenika. Prvi je taj da se nastava stranog jezika ne doživljava kao važan izvor učenja jezika, uz relevantna tekuća saznanja koja se na stranom jeziku prenose. Drugi je ekstremno shvaćena primena komunikativnog pristupa u podučavanju jezika u kome je jezik, i dalje, predstavaljen kroz komunikaciju fokusiranu na gramatičku tačnost, što ne dovodi do buđenja motivacije i stavlja akcenat na prenos znanja o jeziku, umesto na komunikaciju. Stoga, najčešći kontekst u kome se L2 predstavlja još uvek je zasnovan na teorijsko-funkcionalnom planu i programu, te je prestao da budi interesovanje učenika. Ovo se upotpunjuje stavljanjem naglaska na sam prenos znanja, pre nego na komunikaciju, kao i na učenje napamet, umesto gramatičkog napretka (Macaro 2008: 101-108). Integracijom jezika i domenskog sadržaja, CLIL može pokrenuti motivaciju putem davanja opravdanog i autentičnog konteksta za primenu jezika. U okviru CLIL-a, jezik postaje sredstvo pre nego cilj, što vodi ka značajnom stepenu smanjenja anksioznosti koju učenici iskazuju (Lasagabaster i Sierra 2009). CLIL podržava hipotezu afektivnog filtera (po Krašenu, zamišljena barijera koja sprečava učenike da koriste input koji je dostupan u okruženju (Light i Spada 1997: 28)) i potrebu da se učenici osećaju opušteno i spremni su za učenje. Časovi koncipirani oko sadržaja dozvoljavaju učenicima da se uključe u proces učenja na jednom kreativnom i kognitivno izazovnom nivou, i pružaju mogućnosti prirodne interakcije sa ostalima, samim sobom i svetom, a u okviru različitih konteksta (Greenfell 2002: 32). Većini učenika CLIL-a na engleskom jeziku, poznato je da će morati da koriste engleski jezik kao sredstvo za obavljanje drugih aktivnosti, od sticanja znanja do kulturnih proizvoda. Oni zato osećaju jaku instrumentalnu motivaciju, s obzirom na to da učenje drugih predmeta kroz engleski jezik realistično odražava njihovu potrebu. 
CLIL, zatim, pruža mogućnost korišćenja svih kapaciteta učenika, odnosno razvija sve njihove sposobnosti. Zagovornici CLIL nastave smatraju da pored toga što unapređuje veštinu vladanja i poznavanje jezika, on takođe pospešuje jačanje sledećih aspekata: znanja sadržaja, kognitivne veštine, komunikativne senzibilnosti, metalingvističkih kapaciteta, elastičnosti u razmišljanju, kreativnosti, u isto vreme obuhvatajući sposobnosti svih polaznika, a ne samo onih najboljih. Skup istraživanja pokazuje da polaznici CLIL programa nemaju nedostataka u nivou postignuća na prvom jeziku ili na nivou sadržaja predmeta, i da veoma često pokazuju čak i bolje rezultate na različitim nivoima nastave u odnosu na rezultate drugih učenika, koji nisu uključeni u CLIL program. Autor rada dodaje i lična iskustva iz nastave stranog jezika, iz kojih zaključuje da su grupe koje su bile izložene CLIL sadržajima postigle bolje rezultate na usmenom delu završnog testiranja u odnosu na one koje su bile izložene samo gradivu iz redovnih školskih udžbenika. ${ }^{6}$ Dvojni fokus CLIL programa zasnovan na dvostrukoj obradi, mora biti u potpunosti transparentan kako bi postigao intenzivnije usvajanje znanja. Jezik se posmatra i kao instrument učenja, ali i oblast usvajanja koja ima potrebu za potporom i napretkom, kao i sam sadržaj. U tom smislu, CLIL izlaže jezička pitanja u predmetnom sadržaju na način koji je često odsutan u nejezičkim predmetima (Gajo 2007; Baetens Bearsmore 2008; Mehisto 2008; Coyle et al. 2010). Ovo čini nastavnike u okviru (LIL programa svesnijim lingvističkih potreba učenika i na taj način efektivnijim u obezbeđivanju razumevanja (Beko 2013: 19-25).

Kao što je već napomenuto, CLIL podiže nivo interkulturne svesti učenika. CLIL se dovodi u vezu sa razvojem interkulturne svesti time što učenicima pruža iskustvo koje bi bilo nemoguće steći u okviru jednojezičke ili tradicionalne L2 nastave. Mada jezik i kultura predstavaljaju neku vrstu simbioze, rad na samom jeziku ne mora da vodi ka samosvesti i toleranciji razlika povezanih sa interkulturnim razumevanjem (Beko 2013: 24). Upotreba novih tehnologija i partnerstva (npr. sestrinske škole) sa školama u inostranstvu može učiniti da CLIL postane prenosilac interkulturnih iskustava, čime će motivisati nastavnike, a time i učenike, da zauzmu aktivniju ulogu u procesu učenja i time iskoriste što više potencijala CLIL nastave. Autor rada je i sam svedok i učesnik uspešnih razmena kulturoloških iskustava kroz Skype nastavu sa učenicima iz škole jezika iz Rusije ili kroz razmenu paketa sa radovima na engleskom jeziku (Parcel of English Project) sa školom jezika iz Grčke. Sve više postaje praksa i u redovnim školama u Srbiji da se učenici uključuju u direktne kontakte (bilo onlajn, bilo preko programa razmene odeljenja srednjih škola ${ }^{7}$ ) sa učenicima iz drugih zemalja i tako uče 0 kulturi tih naroda kroz upotrebu engleskog jezika. CLIL teoretičari smatraju da je možda najpostojanija tvrdnja vezana za CLIL metodu, ta da ona ima potencijal koji vodi ka višoj interkulturnoj svesti u odnosu na tradicionalne sadržaje ili učenje jezika, odnosno potencijal da učenje kulture bude jezgrovni deo CLIL-a, a ne periferni (Byram i Risager 1999; Coyle et al. 2010;). Kako sve više raste potreba za globalnim osećajem

6 Neobjavljeno istraživanje autora koji je deo rezultata izneo 2010. godine na Drugoj međunarodnoj konferenciji „Language Teaching or Life Teaching: Teaching Foreign Languages to Young Learners: Content and language integrated learning in Teaching Young Learners" na Pedagoškom fakultetu u Jagodini, Univerzitet u Kragujevcu. „Interkultura Srbija” organizuje međunarodnu razmenu učenika, ali i celih odeljenja srednjih škola. 
za pripadanjem, pa time i zajedništvom, ova dimenzija CLIL programa predstavlja veoma važnu osobinu koja ne bi trebalo da bude potisnuta na drugo mesto u odnosu na praktičnije ciljeve unapređivanja jezičkog umeća.

CLIL, putem integrisanog sadržaja i jezika, pruža učenicima izazovnije okruženje od tradicionalnog, što poboljšava usvajanje i učenje jezika, i na taj način vodi ka većem nivou znanja kod učenika (Lyster 2007: 38). CLIL pospešuje sadržaj nastave time što podstiče kognitivni razvoj i fleksibilnost kod učenika, kroz konstruktivistički pristup i prihvatanje jezika kao osnovnog sredstva za učenje (Lyster 2007; Gajo 2007; Coyle et al. 2010). Može se reći da je (LIL celina koja je veća od dva njegova, već pomenuta dela, pružajući obrazovanje koje prelazi granice zadate teme i sadržaja učenja (Beko 2013: 25).

Kao neka vrsta zaključka u vezi sa doprinosom (LIL-a u nastavi stranih jezika, dobre strane grupisane su u sedam tačaka (Zavišin 2013: 30): 1) učenici su izloženi u velikoj meri stranom jeziku u okviru nejezičke nastave na stranom jeziku: jezik u ovom kontekstu ima ulogu usputnog jezika koji mora biti razumljiv, u skladu sa sadržajem i potrebama učenika; 2) jezik se podučava u kontekstu sadržaja, a ne u izolovanim fragmentima, pa učenici imaju česte prilike da slušaju, koriste i pregovaraju o sadržaju koristeći se stranim jezikom: na ovaj način eksplicitno podučavanje jezika upotpunjuje se sa usvajanjem sadržaja; 3) postepeno uvođenje složenih nastavnih materijala omogućava učenicima da se oslanjaju na prethodno stečena znanja kako bi usvojili nove jezičke i nejezičke sadržaje; 4) učenici su izloženi složenim kognitivnim podsticajima i uključeni u zahtevne aktivnosti koje podstiču unutrašnju motivaciju; 5) objedinjavanje sadržaja i jezika podstiče primenu i razvoj kognitivnih strategija: teme nejezičkih predmeta podstiču upotrebu strategija za različite sadržaje i zadatke; 6) usvajanje jezika i sadržaja omogućava fleksibilnost i prilagodljivost kurikuluma i aktivnosti; 7) nastava je usmerena na učenika koji poseduje veću moć odlučivanja u izboru tema i aktivnosti. Svi pomenuti pozitivni efekti potkrepljeni su načelima Gardnerove $^{8}$ teorije višestruke inteligencije jer kada podučavamo nejezički predmet na stranom jeziku moramo se oslanjati na više vrsta inteligencija u radu sa učenicima. $\mathrm{Na}$ taj način, istovremeno sa verbalnom inteligencijom koja preovladava u nastavi jezika, podjednako je zastupljena i inteligencija u vezi sa nejezičkim predmetom, kao na primer muzička, logičko-matematička ili prostorna inteligencija, u zavisnosti od nastavnog predmeta.

\section{POTENCIJALNE PREPREKE CLIL-A}

Skrenuću pažnju i na one elemente koji predstavljaju prepreke uspešnoj implementaciji CLIL nastave u kurikulume škola. Učenje jezika, kao ni CLIL sadržaj sam po sebi, ne može biti isključivi izvor motivacije. Stoga, sledeći faktori, takođe, igraju važnu ulogu u motivaciji, kako instrumentalnoj, tako i integrativnoj, iako sami po

8 Psiholog Hauard Gardner razlikuje sledeće vrste inteligencija: verbalna, muzička, logičko-matematička, vizuelno-spacijalna, kinestetička, interpersonalna, intrapersonalna, naturalistička i egzistencijalistička (spiritualistička). 
sebi ne predstavljaju negativne odrednice. To su: okruženje u učionici, metodologija, udžbenik, prilagođavanje novim sadržajima, održavanje samopoštovanja, realnost šireg iskustva i mnogi drugi.

Kako bi se nadomestili nedostaci u podučavanju L2, CLIL mora biti dopunjen i dobrom praksom u oblasti dobijanja povratne informacije (eng. feedback). Jako je važno reći da, delimični CLIL sadrži elemente upotrebe L1 (maternjeg jezika) čime se sprečava percepcija inferiornosti L1 u učenju jezika, koja je česta u savremenim tokovima metodike nastave stranih jezika. Time CLIL identifikuje potrebu da se održi samopoštovanje polaznika u početnim fazama nastave, kada ne mogu ispratiti sve sadržaje na ciljnom jeziku. Ipak, izbalansirana integracija sadržaja, jezika i saznanja, na koju se oslanja nastava, ne postiže se sa lakoćom i još uvek nije svugde slučaj. Neuspeh u analiziranju i obezbeđivanju jezičkih potreba polaznika vodi ka neizbežnom neuspehu najslabijih učenika (Beko 2013: 22-24). Takođe, sposobnosti predavača su ključna stavka u ovoj oblasti, i ukoliko izostane posebna obuka mogu se stvarati učestale prepreke u vidu kadra (Meyer 2013: 305). Lorencovo istraživanje (Lorenzo 2008) je pokazalo da CLIL predavačima često nedostaje širi repertoar strategija pomoću kojih bi se akademski sadržaj postavio u jezik koji je razumljiv, rastegljiv i postojan sa aspekta domenskog podučavanja. Problem je dodatno iskomplikovan činjenicom da predmetni nastavnici uključeni u CLIL program retko uviđaju da njihov predmet predstavlja mesto za razvoj i uvežbavanje jezika, te da je istog značaja kao i usvajanje sadržaja.

Još neki faktori mogu uticati na uspešnu realizaciju CLIL nastave. Najpre, veliki broj učenika u odeljenjima, što se u nekim našim školama, poput filoloških gimnazija i bilingvalnih gimnazija, rešilo deljenjem učenika na manje grupe. Čak i u neformalnom obrazovanju, u primeru škola stranih jezika, učenje jezika je organizovano kroz posebne kurseve (iskustvo autora rada), najčešce nakon drugih školskih obaveza ili u kasnijim večernjim terminima kada je pažnja manja. Vrlo važan izazov jeste i pitanje neujednačenih grupa ili razreda prema jezičkom znanju, što može dovesti do problema kod izbora jedinica iz određenog sadržaja. Naposletku, jedan od najvažnijih faktora koji negativno mogu da utiču na uspeh CLIL metoda jeste i nedovoljan broj časova u školi.

\section{ZAKLJUČAK}

Kako bi se dosegao pun potencijal CLIL nastave, potreban je holistički metodološki pristup uspostavljanju odnosaizmeđu prenošenja sadržaja ijezika u procesu predavanja. Prelazak sa koncepta prenosa jezika na stvaranje znanja u multilingvalnom okruženju dovodi do potrebe da se drugi jezik koristi za konstrukciju značenja (Coyle et al. 2010). Nakon opisa glavnih elemenata CLIL nastave i prednosti koje ovakav vid nastave donosi u tradicionalno obrazovanje, zaključujem da CLIL obezbeđuje bogat jezički sadržaj koji je autentičan, ima svrhu i izazov. Zatim, kako bi učenici lakše usvojili gradivo, nastavu mora da podržava učenje zasnovano na ko-konstrukciji, čija je uloga da smanji kognitivno opterećenje (eng. cognitive load), obezbedi potporu u struktuiranju učenja i podstiče jezičku produkciju. Kroz bogatu interakciju koju učenici imaju, a koja je 
organizovana kroz prilagođene zadatake u nastavi, dolazi do ostvarivanja očekivanih ishoda u procesu podučavanja. Konačno, CLIL daje značajan doprinos u razvijanju interkulturne kompetencije, kao i razvitku složenijeg procesa razmišljanja.

Ono što će biti dalja sfera interesovanja autora rada, odnosi se na domene, čije rešavanje može doprineti jasnijem sagledavanju CLIL-a, kao i njegovoj uspešnosti u školama u Srbiji i šire. Najpre se ne sme zaboraviti najvažnija činjenica tokom potrage za autentičnim sadržajima za CLIL nastavu, a to je da nastavnik mora predstavljati uzor koji aktivno podučava i pokazuje učenicima kako da koriste jezičke operacije poput analiziranja sadržaja ili verbalizovanja složenih procesa mišljenja. Stoga, dalje istraživanje može revalorizovati ulogu nastavnika u podučavanju i procesu učenja. Neophodno je pronalaženje ravnoteže između upravljanja aktivnostima od strane nastavnika i učenika, kako bi nastavnici mogli da pruže odgovorajuću potporu i motivaciju (Meyer 2013: 297-305).

Kako se već nalazimo u dobu informacione tehnologije, predmet daljeg istraživanja su svakako i veštine mišljenja (H.0.T. ${ }^{9}$ ). Kao što je utvrđeno (Meyer 2013: 305), 80\% pitanja koje nastavnici postavljaju su u vezi sa znanjem činjenica, odnosno najnižim nivoom razmišljanja. Pitanja nastavnikove povratne informacije, ispravljanje grešaka i pogrešaka, ukupnog vrednovanja postignuća, kao i njihovo sprovođenje na jedan sistematičan i profesionalan način, predstavljaju važne domene daljeg istraživanja autora rada. Naposletku, iako se veliki broj radova u vezi sa potencijalom CLIL-a bavi razmatranjem jezika i sadržaja, ne može se zanemariti činjenica da i stavovi učenika, pored pomenute motivacije, treba da budu u fokusu pri postizanju rezultata u CLIL učionici, što može biti interesantno za dalje proučavanje (Papaja 2010: 127).

Kao krajnji zaključak navodim da CLIL nastava doprinosi opštem potencijalu koji obrazovanje treba da ima u oblikovanju života mladih generacija. Stoga, podržavanjem ovakvog vida nastave, podržavamo:

[...] razvijanje vrednosti [...] ličnosti mladih ljudi; stavljanje značaja na emocionalno, kao i kognitivno učenje; građenje posvećenosti životu u grupi [...] ne samo kratkotrajnom radu tima; negovanje kosmopolitskog identiteta koji ispoljava toleranciju prema rasnim i polnim razlikama, iskrenu znatiželju prema drugim kulturama i volji da se od njih uči i odgovornost prema isključenim grupama (Hargreaves 2003: $\mathrm{xix})^{10}$.

9 Eng. Higher Order Thinking

10 "developing the values... of young people's character; emphasizing emotional as well as cognitive learning; building commitments to group life... not just short-term teamwork; cultivating a cosmopolitan identity which shows tolerance of race and gender differences, genuine curiosity towards and willingness to learn from other cultures, and responsibility towards excluded groups." 


\section{LITERATURA}

Badertscher, H. i T. Bieri. 2009. Wissenserwerbim im Content and Language Integrated Learning: Empirische Befunde und Interpretationen. Bern: Haupt.

Baetens-Beardsmore, H. 2008. Multilingualism, Cognition and Creativity. International CLIL Research Journal 1 (1), 1-23.

Beko, L. 2013. Integrisano učenje sadržaja i jezika (CLIL) na geološkim studijama. Filološki fakultet Univerziteta u Beogradu. Neobjavljena doktorska disertacija.

Byram, M. i K. Risager. 1999. Language Teachers, Politics and Cultures. Clevedon, UK: Multilingual Matters.

Coyle, D., P. Hood i D. Marsh. 2010. CLIL. Content and Language Integrated Learning. Cambridge: Cambridge University Press.

Cummins, J. i M. Swain. 1986. Bilingualism in Education. London: Longman.

Dalton-Puffer, C. 2007. Discourse in Content and Language Integrated Learning (CLIL) classrooms. New York, Amsterdam: John Benjamins Publishing Company.

Dalton-Puffer, C., J. Hüttner, V. Schindelegger i U. Smit. 2009. Technology-geeks speak out: What students think about vocational CLIL? International CLIL Research Journal $1(2), 17-25$.

Durbaba, 0., Lj. Đurić, J. Ginić, A. Jovanović, L. Medenica, A. Sekulić, J. Rašević i K. Zavišin. 2017. Opšti standardi postignuća za kraj osnovnog obrazovanja za strani jezik. Beograd: ZVKOV.

Filipović, J., J. Vučo i Lj. Đurić. 2007. Critical Review of Language Education Policies in Compulsory Primary and Secondary Education in Serbia. Current Issues in Language Planning 8 (1), 222-242.

Gajo, L. 2007. Linguistic knowledge and Subject knowledge: how does bilingualism contribute to subject development? International Journal of Bilingual Education and Bilingualism 10 (5), 563-581.

Gardner, H. 2006. Multiple Intelligence: New horizons in theory and practice. New York: The Perseuse Book Group.

Graddol, N. 2006. English Next. London: British Council.

Greenfell, M. (ed.). 2002. Modern Languages across the curriculum. London: Routledge.

Hargreaves, A. 2003. Teaching in the Knowledge Society. Maidenhead: Open UP.

Heine, L. 2008. Task-based Cognition of Bilingual Learners in Subject-specific Contexts.

U J. Eckerth i S. Siekmann (eds.) Task-Based Language Learning and Teaching Theoretical, Methodological, and Pedagogical Perspectives. Frankfurt/M.: Peter Lang, 203-226.

Lasagabaster, D. i J. M. Sierra. 2009. Language attitudes in CLIL and traditional EFL classes. International CLIL Research Journal 1 (2), 4-17.

Lasagabaster, D. i J. M. Sierra. 2010. Immersion and CLIL in English: more differences than similarities. ELT Journal 64 (4), 367-375.

Lightbrown, P. i N. Spada. 1997. How Languages are Learned. Oxford: OUP.

Lorenzo, F. 2008. Instructional discourse in bilingual settings: an empirical study of linguistic adjustments in CLIL. Language Learning Journal 36 (1), 21-23.

Lyster, R. 2007. Learning and teaching languages through Content: A counter-balanced/ approach. Amsterdam/Philadelphia: John Benjamins. 
Macaro, E. 2008. The decline in language learning in England: getting the facts right and getting real. Language Learning Journal 36 (1), 101-108.

Marsh, D.i G. Lange (eds.). 2000. Using Languages to Learnand Learning to Use Languages. An introduction to Content and Language Integrated Learning for Parents and Young People. Jyväskylä, Finland: University of Jyväskylä.

Mehisto, P., D. Marsh i M. Frigols. 2008. Uncovering CLIL: Content and Language Integrated Learning in Bilingual and Multilingual Education. Oxford: Macmillan.

Meyer, 0. 2013. Introducing the CLIL-Pyramid: Key Strategies and Principles for CLIL Planning and Teaching. [Internet]. Dostupno na: https://www.researchgate.net/ publication/275887754 [8.10.2019].

Papaja, K. 2010 Qualitative Evaluation of Content and Language Integrated Learning (CLIL) in Polish Secondary Education. Faculty of Philology, Institute of English, Katowice. Neobjavljena doktorska disertacija.

Tedick, D. i L. Cammarata. 2012. Content and language integration in K-12 contexts: Student outcomes, teacher practices, and stakeholder perspectives. Foreign Language Annals 45 (1), 28-53.

Vámos, Á. 1998 The Hungarian Map of Languages of Instruction. Budapest: Keraban. [Internet]. Dostupno na: http://archive.ecml.at/mtp2/ensemble/results/Kapitanffy. $\mathrm{htm}$ [31.10.2019].

Vučo, J. 2006. U potrazi za sopstvenim modelom dvojezične nastave. Inovacije u nastavi XIX, 41-54.

Wolff, D. 2003. Contentand languageintegrated learning: a framework for the development of learner autonomy. U D. Little, J. Ridley i E. Ushioda (eds.) Learner Autonomy in the Foreign Language Classroom: Teacher,Learner, Curriculum and Assessment. Dublin: Authentik, 211-222.

Zavišin, K. 2013. Teorijske osnove i kritička analiza CLIL nastave na italijanskom $i$ srpskom jeziku u srednjoj školi u Srbiji. Filološki fakultet Univerziteta u Beogradu. Neobjavljena doktorska disertacija.

\section{SUMMARY}

\section{THE CONTRIBUTION OF CLIL TO CONTEMPORARY TRENDS OF FOREIGN LANGUAGE TEACHING}

The communicative approach of second language teaching has entered many schools in different educational systems worldwide. The reforms that follow sociopolitical and education quality tendencies in the country and elsewhere require clearer objectives in the implementation of productive acquisition of second language in educational systems. One such successful model in second language teaching is integrated learning of content and language (CLIL). With its rising popularity CLIL method represents a solution for motivating students, fostering teaching related to linguistic aspects of foreign languages through acquiring general knowledge and reaching outcomes which are applicable not only in the area of social communication but also in academic advancement towards complex processes of thinking. This paper 
offers an insight into characteristics and development of (LIL (in Serbia and abroad) so that the practitioners in the classroom could reach the full potential of CLIL. The paper also provides effects gained by successful application of CLIL. I conclude that CLIL has a future in Serbia, as it does across the boarders. The paper tackles some obstacles which should be addressed in the implementation of this form of teaching and suggests further fields of research.

KEYWORDS: CLIL, benefits, L2, motivation, content.

PODACI 0 ČLANKU: Pregledni rad

Primljen: 15. decembar 2019. Ispravljen: 19. januar 2020. Prihvaćen: 1. februar 2020. 